\title{
Abnormal Sympathetic Overactivity Evoked by Insulin in the Skeletal Muscle of Patients with Essential Hypertension
}

\author{
Giuseppe Lembo, Raffaele Napoli, Brunella Capaldo, Virgilio Rendina, Guido laccarino, \\ Massimo Volpe, Bruno Trimarco, and Luigi Saccà \\ Department of Internal Medicine, II School of Medicine, Federico II University, 80131 Napoli, Italy
}

\begin{abstract}
The reason why hyperinsulinemia is associated with essential hypertension is not known. To test the hypothesis of a pathophysiologic link mediated by the sympathetic nervous system, we measured the changes in forearm norepinephrine release, by using the forearm perfusion technique in conjunction with the infusion of tritiated NE, in patients with essential hypertension and in normal subjects receiving insulin intravenously $(1 \mathrm{mU} /$ kg per min) while maintaining euglycemia.

Hyperinsulinemia (50-60 $\mu \mathrm{U} / \mathrm{ml}$ in the deep forearm vein) evoked a significant increase in forearm NE release in both groups of subjects. However, the response of hypertensives was threefold greater compared to that of normotensives $(2.28 \pm 45$ $\mathrm{ng} \cdot$ liter $^{-1} \cdot \mathrm{min}^{-1}$ in hypertensives and $0.80 \pm 0.27 \mathrm{ng} \cdot$ liter $^{-1}$ in normals; $P<0.01$ ). Forearm glucose uptake rose to $5.1 \pm .7$ $\mathrm{mg} \cdot \operatorname{liter}^{-1} \cdot \mathrm{min}^{-1}$ in response to insulin in hypertensives and to $7.9 \pm 1.3 \mathrm{mg} \cdot \operatorname{liter}^{1} \cdot \mathrm{min}^{-1}$ in normotensives $(P<0.05)$.

To clarify whether insulin action was due to a direct effect on muscle NE metabolism, in another set of experiments insulin was infused locally into the brachial artery to expose only the forearm tissues to the same insulin levels as in the systemic studies. During local hyperinsulinemia, forearm NE release remained virtually unchanged both in hypertensive and in normal subjects. Furthermore, forearm glucose disposal was activated to a similar extent in both groups $(5.0 \pm 0.6$ and $5.2 \pm 1.1$ $\mathrm{mg} \cdot \mathrm{liter}^{-1} \cdot \mathrm{min}^{-1}$ in hypertensives and in normals, respectively). These data demonstrate that: $(a)$ insulin evokes an abnormal muscle sympathetic overactivity in essential hypertension which is mediated by mechanisms involving the central nervous system; and (b) insulin resistance associated with hypertension is demonstrable in the skeletal muscle tissue only with systemic insulin administration which produces muscle sympathetic overactivity. The data fit the hypothesis that the sympathetic system mediates the pathophysiologic link between hyperinsulinemia and essential hypertension. (J. Clin. Invest. 1992.90:24-29.) Key words: hypertension • insulin resistance • sympathetic nervous system • norepinephrine release • glucose
\end{abstract}

This work was presented in part at the High Blood Pressure Council 45th Annual Fall Conference, Chicago, IL, 24-27 September 1991.

Address correspondence to Bruno Trimarco, M. D., Medicina Interna, Via Pansini 5, 80131 Napoli, Italy.

Received for publication 23 September 1991 and in revised form 14 February 1992.

J. Clin. Invest.

(c) The American Society for Clinical Investigation, Inc. 0021-9738/92/07/0024/06 \$2.00

Volume 90, July 1992, 24-29

\section{Introduction}

Although the coexistence of hyperinsulinemia and essential hypertension has long been recognized (1-3), the nature and the significance of this association are far from being completely elucidated. A critical question is whether hyperinsulinemia is causally related to the development of hypertension and, if so, what mechanism underlies insulin action on blood pressure regulation. The question is under active investigation but the data available so far are not entirely consistent. Substantial evidence favoring a causal role of insulin comes essentially from the studies in fructose-fed rats (4-6). In this model, insulin resistance, hyperinsulinemia, and hypertension develop and this sequence may be interrupted by preventing either insulin resistance with physical exercise or hyperinsulinemia with somatostatin $(5,6)$.

The relationship between insulin and human hypertension has been extensively investigated on epidemiological ground, less so from a mechanistic standpoint. The available clinical data, however, tend to support the concept that the two factors must be linked by pathophysiologic mechanisms. Particularly relevant is the observation that a program of physical activity or body weight control leads to a parallel reduction of hyperinsulinemia and blood pressure levels (7). Of interest is also the recent observation that in the offspring of essential hypertensive parents insulin resistance and hyperinsulinemia are demonstrable before the development of high blood pressure (8).

Among the various factors considered as potential links between insulin and blood pressure, the sympathetic nervous system is indicated as a prime candidate for a number of reasons: (a) in hypertensive patients, glucose intolerance and insulin resistance with attendant hyperinsulinemia have been amply demonstrated $(3,9,10) ;(b)$ in normal individuals, insulin evokes sympathetic overactivity $(11,12)$; $(c)$ increased sympathetic activity in essential hypertension, particularly in the mild form of young hypertensives, has been documented by a variety of approaches $(13,14)$; and $(d)$ sympathetic overactivity may be potentially responsible for elevated blood pressure (15) and may antagonize insulin action (16-20). Based on these findings, a hypothetical sequence may be formulated where hyperinsulinemia leads to sympathetic overactivity which, on the one hand, raises blood pressure and, on the other hand, deteriorates insulin sensitivity, thus aggravating the initial hyperinsulinemia. A crucial point in this construction is the need to demonstrate that the sympathetic nervous system does respond abnormally to insulin stimulation in hypertensive subjects. The current study was designed to explore this specific question. In particular, we used the forearm perfusion technique in conjunction with a tracer method $\left({ }^{3} \mathrm{H}\right]$ norepinephrine) to measure the changes in NE release by the skeletal muscle induced by physiological hyperinsulinemia in normal subjects and in hypertensive patients. 
The study was performed at skeletal muscle level as this tissue is an important site of insulin action in general and is specifically responsible for insulin resistance in human hypertension (21). It must be also remarked that the skeletal muscle is involved in catecholamine-induced insulin resistance in humans $(19,22)$. Thus, information on insulin-norepinephrine interaction in the muscle tissue of hypertensives could be particularly relevant to the question whether hyperinsulinemia and hypertension indeed have a pathophysiologic link in common.

\section{Methods}

Subjects. The study group consisted of 45 subjects, 21 normotensives, and 24 patients with established mild to moderate essential hypertension. The most relevant clinical characteristics of the subjects are given in Table I. Diagnosis of hypertension was based on at least five consecutive readings of diastolic blood pressure exceeding $95 \mathrm{mmHg}$ in the outpatient clinic. Blood pressure was measured with the patient in the supine position, after $10 \mathrm{~min}$ resting in a darkened room, by means of a standard sphygmomanometer with a cuff of appropriate size, following the recommendations of the American Heart Association (23). None of the patients had received any treatment for at least one month before the study. A complete medical work-up was carried out to exclude secondary forms of hypertension. Renal, liver, and endocrine functions were normal. No patient had recent changes in body weight or dietary habits, and none had intercurrent illnesses. Normal body weight ( $<20 \%$ above or below desirable body weight, according to life insurance tables [24]) and normal tolerance to a 75-g oral glucose load (according to the criteria of the National Diabetes Data Group [25]) were additional criteria for the inclusion in the study. No subject was engaged in competitive sports or did intense physical activity during the two days preceding the study. Written informed consent was obtained from all participants. The experimental protocol was approved by the Ethical Committee of the University of Naples School of Medicine.

Procedures. The studies were begun at $8 \mathrm{a} . \mathrm{m}$. in a quiet room with a constant temperature of $22-24^{\circ} \mathrm{C}$. All subjects were studied in the postabsorptive state in the supine position after 12- to 15 -h overnight fast. The forearm perfusion technique (26) was performed as previously described (27). A plastic cannula was introduced in a retrograde manner into a large antecubital vein and threaded as deeply as possible. Under these conditions, the effluent venous blood drained predominantly muscle tissue. A second cannula was inserted into the ipsilateral brachial artery. This was used for infusion of indocyanine green dye (Cardio-Green; Hynson, Westcott, and Dunning Products, Baltimore, MD) to measure forearm blood flow, as well as to sample blood entering the forearm and to measure systemic arterial pressure by means of Statham P23Db pressure transducer (Gould, Inc., Instruments Div., Cleveland, $\mathrm{OH})$. Systolic and diastolic blood pressure were simultaneously recorded on a multichannel polygraph (Gould Inc., Medical Products Div., Oxnard, CA). An electrocardiographic lead was monitored during the study to measure heart rate. A contralateral arm vein was also cannulated for the infusion of test substances. During blood collection, a sphygmomanometer cuff placed around the wrist was inflated $100 \mathrm{mmHg}$ above the systolic arterial pressure to exclude the hand from the circulation. Soon after blood collection, indocyanine

Table I. Clinical Characteristics of the Subjects

\begin{tabular}{lcccc}
\hline & Age & Sex & Body mass index & Mean arterial pressure \\
& $y r$ & M:F & $k g / m^{2}$ & $\mathrm{mmHg}$ \\
Normotensives & $33 \pm 3^{*}$ & $15: 6$ & $25.4 \pm 0.4$ & $98 \pm 2$ \\
Hypertensives & $36 \pm 2$ & $17: 7$ & $25.2 \pm 0.5$ & $127 \pm 2^{\ddagger}$
\end{tabular}

${ }^{*}$ Mean \pm SE. ${ }^{\ddagger} P<0.05$ (unpaired $t$ test). green dye was infused through the arterial catheter, while keeping the cuff inflated around the wrist. After 4-5 min, a venous blood sample was taken to measure the plasma concentration of the dye.

After complete instrumentation, a minimum of $30 \mathrm{~min}$ of quiet rest preceded the three measurements of basal hemodynamics and venous and arterial blood samplings, made at 15 -min intervals. Afterwards, one of the following protocols was performed: $(a)$ systemic insulin infusion, or $(b)$ intrabrachial insulin infusion. In the systemic insulinization protocol, the subjects ( 12 normals and 14 hypertensives) received an infusion of human regular insulin into a contralateral vein at a rate of 1 $\mathrm{mU} / \mathrm{kg}$ per min for $120 \mathrm{~min}$ to raise peripheral insulin concentration to levels comparable to those normally achieved postprandially $(\approx 60$ $\mu \mathrm{U} / \mathrm{ml}$ ). To maintain plasma glucose at its basal value, in spite of systemic hyperinsulinemia, a variable amount of glucose was also infused. The glucose infusion rate was adjusted by measuring arterial plasma glucose levels at 5-min intervals by means of a glucose analyzer (Beckman Instruments, Fullerton, CA). In the local insulinization protocol, the subjects ( 9 normals and 10 hypertensives) received human regular insulin directly into the brachial artery at a rate of $0.05 \mathrm{mU} / \mathrm{kg}$ per min. This rate was chosen so as to expose the forearm tissues to a comparable insulin concentration to that achieved with systemic insulinization (28). For this purpose, a double lumen catheter with the distal hole separated by $\approx 4 \mathrm{~cm}$ from the proximal one (Arrow International Inc., Reading, PA) was introduced into the brachial artery. The distal lumen was used for insulin and green dye infusion, whereas the proximal lumen was used to sample arterial blood entering the forearm, uncontaminated by solutions infused downstream, and to measure arterial blood pressure. Arterial and venous blood sampling and blood flow measurements were performed at 60,90 , and 120 min during either systemic or local insulin administration.

A potential problem with intraarterial infusion is that the infusate may not completely mix with the arterial blood, thus resulting in streaming and not uniform exposure of forearm tissues to the infused substance. As reported in a previous study (28), we tried to minimize this problem and assessed its importance by checking the concentration of the intraarterially infused dye in two different veins draining the forearm. We found that lack of significant streaming (dye concentration difference $<20 \%$ ) occurred in almost $90 \%$ of the tested cases $(n=16)$.

As specified below, net NE balance across the forearm muscle was calculated as the product of the arterial $(\mathrm{A})^{1}$-venous $(\mathrm{V})$ concentration difference and the forearm plasma flow. However, forearm NE balance represents the algebraic sum of production and uptake of the neurotransmitter. To understand the mechanism whereby a given change in NE balance occurs, it is necessary to quantify the two processes separately. To this end, NE release was directly measured in subgroups of subjects by using simultaneously the balance approach, as described above, together with a tracer technique based on primed constant infusion of tritiated norepinephrine. This combined balance-tracer approach was performed in eight normals and seven hypertensives in the systemic insulin infusion protocol and in five normals and five hypertensives in the local insulin protocol. In particular, 40 min before starting insulin administration, the subjects received intravenously a priming dose $(27 \mu \mathrm{Ci})$ of $\mathrm{L}-\left[2,5,6-{ }^{3} \mathrm{H}\right]$ norepinephrine (New England $\mathrm{Nu}$ clear, Boston, MA; sp act $43.7 \mathrm{Ci} / \mathrm{mmol}$ ) diluted in $0.9 \%$ saline containing ascorbic acid $(2 \mathrm{mg} / \mathrm{ml})$, followed by a constant infusion $(0.63 \mu \mathrm{Ci} / \mathrm{min})$ which was continued throughout the study period.

Analytical methods. Plasma glucose (PG) was determined on a glucose analyzer (Beckman Instruments) and converted to blood glucose (BG) by using the formula $\mathrm{BG}=\mathrm{PG}(1-0.3 \times$ hematocrit). Plasma FFA concentration was measured by an enzymatic procedure (29). Plasma insulin was measured by radioimmunoassay (30). The plasma concentration of indocyanine green dye was measured spectrophotometrically. Plasma catecholamines were partially purified by batch alu-

1. Abbreviations used in this paper: A, arterial; FNU, forearm NE uptake; $\mathrm{V}$, venous. 
Table II. Effects of Systemic Insulin Administration on Hemodynamic Parameters

\begin{tabular}{clccc}
\hline & & $\begin{array}{c}\text { Systolic arterial } \\
\text { pressure }\end{array}$ & $\begin{array}{c}\text { Diastolic arterial } \\
\text { pressure }\end{array}$ & Heart rate \\
\hline & & $m m H g$ & $m m H g$ & beats $/$ min \\
$\begin{array}{c}\text { Normotensives } \\
(n=12)\end{array}$ & Base & $135 \pm 3^{*}$ & $73 \pm 2$ & $67 \pm 2$ \\
& Insulin & $138 \pm 4$ & $74 \pm 2$ & $67 \pm 3$ \\
$\begin{array}{c}\text { Hypertensives } \\
(n=14)\end{array}$ & Base & $168 \pm 4^{\ddagger}$ & $95 \pm 2^{\S}$ & $68 \pm 2$ \\
& Insulin & $167 \pm 5$ & $93 \pm 3$ & $72 \pm 2^{\S}$ \\
& & & & \\
\hline
\end{tabular}

* Mean \pm SE. ${ }^{\ddagger} P<0.01$ as compared with normotensives (unpaired $t$ test). ${ }^{8} P<0.05$ as compared with baseline (paired $t$ test).

mina extraction (31), separated using ion-pairing reverse phase high pressure liquid chromatography ( $\mu$ Bondapak $\mathrm{C} 18$ column, Powerline 600A chromatography system, and WISP 700 as autoinjector; Waters Associates, Millipore Corp., Milford, MA), and quantified by a current produced upon exposure of the column effluent to oxidizing and then reducing potentials connected in series (Coulochem 5100A; ESA, Inc., Bedford, MA) (32). Recovery through the alumina extraction step, calculated using dihydroxybenzylamine as an internal standard, ranged 60-70\% and each sample was corrected for its recovery. Detection limits were $3 \mathrm{pg}$ and $5 \mathrm{pg}$ injected for norepinephrine and epinephrine, respectively. Intraassay and interassay variation coefficients for norepinephrine were 4.1 and $9.8 \%$, and for epinephrine were 6.2 and $12 \%$, respectively. The amount of $\left[{ }^{3} \mathrm{H}\right]$ norepinephrine in plasma and infusate were measured in fractions of the column effluent corresponding in retention time to that of norepinephrine. The fractions were collected into scintillation vials using a fraction collector (Helirac; LKB Instruments Inc., Bromma, Sweden) and the tritium was assayed by liquid scintillation spectrometry (Tricarb Liquid Scintillation Analyzer 2000 CA; Packard Instrument Co., Inc., United Technologies, Downers Grove, IL).

Calculations and data analysis. Whole body glucose uptake expressed as molar value represents the glucose infused to maintain basal glycemic levels during the last $\mathbf{4 0} \mathrm{min}$ of the study period. Forearm plasma flow was estimated by dividing the dye infusion rate by its concentration in the venous plasma and converted to blood flow according to the hematocrit. The forearm balance was calculated by multiplying the arterial-deep vein concentration difference by the forearm blood (glucose) or plasma (NE) flow and was normalized by the forearm volume in liters calculated by water displacement. Positive or negative balance values indicate uptake or release, respectively.
The forearm fractional extraction (FE) of $\left[{ }^{3} \mathrm{H}\right]$ norepinephrine was calculated by the equation: $\mathrm{FE}=(\mathrm{A}-\mathrm{V}) / \mathrm{A}$; where $\mathrm{A}$ and $\mathrm{V}$ are plasma concentrations of tritiated $\mathrm{NE}$ in arterial and venous samples, respectively. NE clearance was obtained by multiplying NE fractional extraction by the forearm plasma flow. Forearm NE uptake (FNU) was thus obtained according to the formula: FNU $=$ NE clearance $\times$ arterial NE concentration. Once FNU was calculated, forearm NE release was easily obtained by subtracting FNU from the net NE balance.

For each parameter the three observations made in the basal state $(-30,-15$, and $0 \mathrm{~min})$ or during insulin infusion $(60,90$, and $120 \mathrm{~min})$ were averaged. This was possible since within each condition (basal or insulin period) there was no statistical difference in the mean values of the various parameters (two-way analysis of variance). Thus, subsequent statistical analysis to test insulin's effect was performed by the paired $t$ test since only two means were involved. The unpaired $t$ test was used to compare normotensives with hypertensives. Results are presented as mean \pm SE.

\section{Results}

Systemic insulinization. As expected, systolic and diastolic blood pressures were significantly higher in hypertensives than in normotensives, and did not change significantly during insulin infusion in both groups (Table II). Heart rate was comparable in the two groups in basal conditions and increased slightly during hyperinsulinemia only in hypertensive patients $(P$ $<0.05$ ). Estimated forearm blood flow was similar in the two groups in the basal state and increased slightly but not significantly after insulin administration (Table III).

As shown in Table III, basal arterial blood glucose concentrations were similar in normal and hypertensive subjects, and remained virtually unchanged during insulin infusion in both groups. Plasma insulin concentration in the deep forearm vein was similar in the basal state in the two groups and increased to a comparable extent during systemic insulin infusion. Whole body glucose utilization ( $M$ value) rose to $5.8 \pm 0.5$ and $4.6 \pm 0.3$ $\mathrm{mg} / \mathrm{kg}$ per min in response to insulin in normotensives and hypertensives, respectively $(P<0.05)$. Forearm glucose uptake in the basal state was not statistically different in normal and hypertensive subjects and increased considerably in response to insulin infusion in both groups. However, the levels attained in hypertensive patients were significantly lower than those observed in control subjects $(P<0.05)$ (Table III).

In normal subjects, forearm NE balance was statistically indistinguishable from zero both in the basal state and during insulin infusion. In contrast, in the hypertensive patients forearm NE balance increased fourfold during hyperinsulinemia $(P$

Table III. Effects of Systemic Insulin Administration on Glucose and Norepinephrine Metabolism in the Forearm Skeletal Muscle

\begin{tabular}{|c|c|c|c|c|c|c|c|}
\hline & & $\begin{array}{l}\text { Deep-vein plasma } \\
\text { insulin }\end{array}$ & $\begin{array}{c}\text { Forearm blood } \\
\text { flow }\end{array}$ & $\begin{array}{l}\text { Arterial blood } \\
\text { glucose }\end{array}$ & $\begin{array}{l}\text { Glucose } \\
\text { uptake }\end{array}$ & $\begin{array}{l}\text { Arterial plasma } \\
\text { norepinephrine }\end{array}$ & $\begin{array}{l}\text { Norepinephrine } \\
\text { balance }\end{array}$ \\
\hline & & $\mu U / m l$ & $\mathrm{ml} \cdot \mathrm{liter}^{-1} \cdot \mathrm{min}^{-1}$ & $m g / d l$ & $m g \cdot$ liter $^{-1} \cdot \mathrm{min}^{-1}$ & $p g / m l$ & $n g \cdot$ liter $^{-1} \cdot \min ^{-1}$ \\
\hline \multicolumn{8}{|c|}{ Normotensives } \\
\hline \multirow[t]{2}{*}{$(n=12)$} & Base & $5 \pm 1^{*}$ & $32 \pm 4$ & $80 \pm 2$ & $1.1 \pm 0.2$ & $197 \pm 19$ & $0.17 \pm 0.29$ \\
\hline & Insulin & $51 \pm 7^{\ddagger}$ & $35 \pm 5$ & $78 \pm 2$ & . $7.9 \pm 1.3^{\ddagger}$ & $278 \pm 28^{\ddagger}$ & $-0.15 \pm 0.37$ \\
\hline \multicolumn{8}{|c|}{ Hypertensives } \\
\hline \multirow[t]{2}{*}{$(n=14)$} & Base & $6 \pm 1$ & $31 \pm 4$ & $79 \pm 3$ & $1.3 \pm 0.4$ & $180 \pm 22$ & $-0.34 \pm 0.27$ \\
\hline & Insulin & $56 \pm 7^{\ddagger}$ & $34 \pm 4$ & $78 \pm 2$ & $5.1 \pm 0.7^{\S \ddagger}$ & $244 \pm 25^{\prime \prime}$ & $-1.47 \pm 0.54^{ \pm 5}$ \\
\hline
\end{tabular}

${ }^{*}$ Mean \pm SE. ${ }^{\ddagger} P<0.05$ as compared with baseline (paired $t$ test). $\quad P<0.001$ as compared with baseline (paired $t$ test). ${ }^{8} P<0.05$ as compared with normotensives (unpaired $t$ test). 
Table IV. Effects of Systemic and Local Insulin Administration on Forearm Norepinephrine Kinetics

\begin{tabular}{|c|c|c|c|c|c|c|c|c|}
\hline & & $\begin{array}{c}\text { Arterial plasma } \\
\text { NE }\end{array}$ & $\begin{array}{c}\text { Arterial } \\
\text { plasma }{ }^{3} \mathrm{H}-\mathrm{NE}\end{array}$ & $\begin{array}{c}\text { A-V } \\
\text { plasma }{ }^{3} \mathrm{H}-\mathrm{NE}\end{array}$ & $\begin{array}{l}\text { NE fractional } \\
\text { extraction }\end{array}$ & $\begin{array}{l}\text { Forearm NE } \\
\text { clearance }\end{array}$ & $\begin{array}{c}\text { Forearm NE } \\
\text { uptake }\end{array}$ & $\begin{array}{l}\text { Forearm NE } \\
\text { release }\end{array}$ \\
\hline & & $p g / m l$ & $d p m / m l$ & $d p m / m l$ & $\%$ & $\mathrm{ml} \cdot$ liter $^{-1} \cdot \mathrm{min}^{-1}$ & ng $\cdot$ liter ${ }^{-1} \cdot \min ^{-1}$ & ng $\cdot$ liter $^{-1} \cdot \min ^{-1}$ \\
\hline \multicolumn{9}{|c|}{ Normotensives } \\
\hline \multirow[t]{2}{*}{$(n=8)$} & Base & $197 \pm 28^{*}$ & $470 \pm 38$ & $344 \pm 43$ & $70 \pm 5$ & $12 \pm 2$ & $2.18 \pm 0.33$ & $2.33 \pm 0.55$ \\
\hline & Systemic insulin & $265 \pm 28^{\ddagger}$ & $483 \pm 56$ & $321 \pm 52$ & $65 \pm 5$ & $11 \pm 1$ & $2.74 \pm 0.43^{\ddagger}$ & $3.13 \pm 0.71^{\ddagger}$ \\
\hline \multicolumn{9}{|c|}{ Hypertensives } \\
\hline \multirow[t]{2}{*}{$(n=7)$} & Base & $169 \pm 29$ & $520 \pm 69$ & $344 \pm 44$ & $67 \pm 3$ & $9 \pm 1$ & $1.71 \pm 0.28$ & $1.63 \pm 0.30$ \\
\hline & Systemic insulin & $235 \pm 39^{\ddagger}$ & $525 \pm 80$ & $352 \pm 63$ & $64 \pm 2$ & $11 \pm 1$ & $2.70 \pm 0.37^{\ddagger}$ & $3.91 \pm 0.62^{\S}$ \\
\hline \multicolumn{9}{|c|}{ Normotensives } \\
\hline \multirow[t]{2}{*}{$(n=5)$} & Base & $137 \pm 14$ & $425 \pm 51$ & $295 \pm 58$ & $67 \pm 6$ & $13 \pm 3$ & $1.96 \pm 0.56$ & $1.95 \pm 0.71$ \\
\hline & Local insulin & $142 \pm 18$ & $456 \pm 84$ & $306 \pm 84$ & $64 \pm 6$ & $14 \pm 4$ & $2.10 \pm 0.80$ & $1.99 \pm 0.93$ \\
\hline \multicolumn{9}{|c|}{ Hypertensives } \\
\hline \multirow[t]{2}{*}{$(n=5)$} & Base & $207 \pm 38$ & $541 \pm 13$ & $403 \pm 11$ & $74 \pm 2$ & $10 \pm 1$ & $2.04 \pm 0.28$ & $2.10 \pm 0.37$ \\
\hline & Local insulin & $207 \pm 29$ & $594 \pm 20$ & $427 \pm 16$ & $67 \pm 5$ & $10 \pm 1$ & $2.17 \pm 0.46$ & $2.09 \pm 0.55$ \\
\hline
\end{tabular}

${ }^{*}$ Mean \pm SE. ${ }^{\ddagger} P<0.05$ as compared with baseline (paired $t$ test). ${ }^{\S} P<0.001$ as compared with baseline (paired $t$ test).

$<0.05$ ), thus becoming a substantial net production (Table III).

Table IV reports the changes in NE kinetics induced by insulin in the subgroup of subjects receiving $\left[{ }^{3} \mathrm{H}\right]$ norepinephrine. The basic data used for the calculations are also reported. Comparable values of NE fractional extraction and clearance were found during both the basal state and the hyperinsulinemic period. Accordingly, forearm NE uptake was similar in the basal state and increased comparably in the two groups during insulin infusion $(P<0.05)$. During the hyperinsulinemic period, forearm NE release increased significantly by $35 \%$ in normotensives $(P<0.05)$. This response was considerably greater in the hypertensive patients in whom forearm NE release increased by $140 \%(P<0.001)$. The mean absolute change in forearm NE release during hyperinsulinemia was threefold higher in hypertensive $\left(2.28 \pm 0.45 \mathrm{ng} \cdot \operatorname{liter}^{-1} \cdot \mathrm{min}^{-1}\right)$ than in normotensive subjects $\left(0.80 \pm 0.27 \mathrm{ng} \cdot\right.$ liter $\left.^{-1} \cdot \mathrm{min}^{-1}\right)$ $(P<0.01)$ (Fig. 1).

Local insulinization. The effects of local insulin infusion are summarized in Tables IV and V. Forearm blood flow increased in both groups during intrabrachial insulin infusion (0.05 $<P<0.1$ in normotensives and $P<0.05$ in hypertensives). Arterial blood glucose levels remained unchanged in both groups during local, intrabrachial insulin infusion. Venous plasma insulin levels increased to the same extent after insulin whereas systemic insulin concentration remained stable at its basal level. Forearm glucose uptake increased in response to intraarterial insulin infusion to a comparable extent in both groups. Forearm NE balance remained unchanged during local insulin administration in both groups of subjects (Table V). Arterial plasma FFA levels were not affected by local insulin (from $0.42 \pm 0.05$ to $0.39 \pm 0.04 \mathrm{mmol}$ in normal subjects and from $0.36 \pm 0.05$ to $0.39 \pm 0.05 \mathrm{mmol}$ in hypertensives).

The effects of intrabrachial insulin infusion on NE kinetics in the subgroup of subjects receiving $\left[{ }^{3} \mathrm{H}\right]$ norepinephrine are shown in Table IV and Fig. 1. Both forearm NE uptake and NE release were totally unaffected by local forearm insulinization.

\section{Discussion}

In this study we explored the responsiveness of the sympathetic nervous system to hyperinsulinemia in essential hypertension. Our interest was focused on the skeletal muscle since this tissue is a primary site of insulin resistance in essential hypertension (21) and is also involved in the insulin antagonistic effect of catecholamines $(18,19,22)$. Thus, a potential connection of insulin to hypertension of more than associative nature was likely to be revealed by investigating this specific tissue.

Our results demonstrate that physiologic hyperinsulinemia increases NE release from the forearm muscle in normal humans. More important, this response is considerably more pronounced in patients with essential hypertension.

The ability of insulin to activate the sympathetic system in normal individuals has been long postulated, based on the finding of increased circulating NE levels (11). More convincing evidence has been recently provided by microneurographic studies documenting an insulin effect on muscle sympathetic nerves $(12,33)$. The current data are well in agreement with

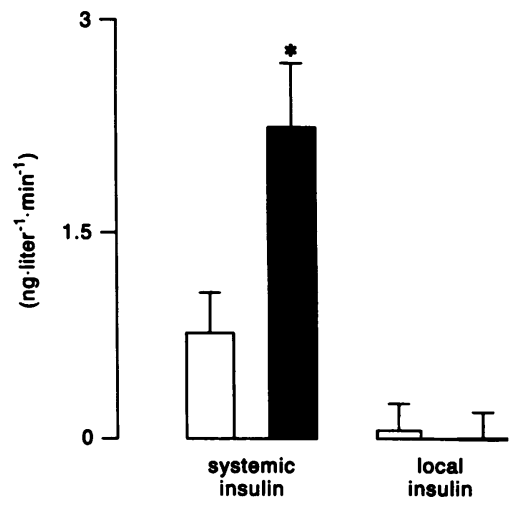

Figure 1. Effect of systemic and local (intrabrachial) insulin administration on forearm NE release. Nine hypertensives and eight control subjects were studied with systemic insulin, whereas five hypertensives and five control subjects were studied with local insulin. The data are expressed as absolute increments above the basal value.

The asterisk indicates a statistically significant difference at $P<0.01$ level as compared with normotensives (unpaired $t$ test). $\square$, Normals; a, hypertensives. 
Table V. Effects of Intrabrachial Insulin Administration on Glucose and Norepinephrine Metabolism in the Forearm Skeletal Muscle

\begin{tabular}{|c|c|c|c|c|c|c|c|}
\hline & & $\begin{array}{l}\text { Deep-vein plasma } \\
\text { insulin }\end{array}$ & $\begin{array}{c}\text { Forearm blood } \\
\text { flow }\end{array}$ & $\begin{array}{l}\text { Arterial blood } \\
\text { glucose }\end{array}$ & $\begin{array}{l}\text { Glucose } \\
\text { uptake }\end{array}$ & $\begin{array}{l}\text { Arterial plasma } \\
\text { norepinephrine }\end{array}$ & $\begin{array}{l}\text { Norepinephrine } \\
\text { balance }\end{array}$ \\
\hline & & $\mu U / m l$ & $\mathrm{ml} \cdot$ liter $^{-1} \cdot \mathrm{min}^{-1}$ & $m g / d l$ & $m g \cdot$ liter $^{-1} \cdot \mathrm{min}^{-1}$ & $p g / m l$ & $n g \cdot$ liter $^{-1} \cdot \min ^{-1}$ \\
\hline \multicolumn{8}{|c|}{ Normotensives } \\
\hline \multirow[t]{2}{*}{$(n=9)$} & Base & $6 \pm 1^{*}$ & $36 \pm 5$ & $82 \pm 2$ & $1.1 \pm 0.3$ & $148 \pm 12$ & $0.02 \pm 0.16$ \\
\hline & Insulin & $54 \pm 13^{\ddagger}$ & $43 \pm 6$ & $82 \pm 2$ & $5.0 \pm 0.6^{\ddagger}$ & $154 \pm 15$ & $0.13 \pm 0.13$ \\
\hline \multicolumn{8}{|c|}{ Hypertensives } \\
\hline \multirow[t]{2}{*}{$(n=10)$} & Base & $5 \pm 1$ & $31 \pm 4$ & $82 \pm 2$ & $1.4 \pm 0.5$ & $171 \pm 28$ & $-0.15 \pm 0.12$ \\
\hline & Insulin & $60 \pm 8^{\ddagger}$ & $37 \pm 6^{\ddagger}$ & $81 \pm 2$ & $5.2 \pm 1.1^{\ddagger}$ & $177 \pm 26$ & $0.11 \pm 0.11$ \\
\hline
\end{tabular}

${ }^{*}$ Mean \pm SE. ${ }^{\ddagger} P<0.05$ as compared with baseline (paired $t$ test).

and extend those observations by providing quantitative data, not previously available, on insulin activation of NE flux from the muscle tissue.

The mechanism by which insulin evokes muscle sympathetic overactivity is not known. The available evidence would suggest several possibilities: $(a)$ an action on the central nervous system (ventro-medial hypothalamic neurons) (34-38); (b) an indirect action mediated by a baroreflex mechanism (12); and (c) a direct effect on muscle NE metabolism. Evidence to support this last hypothesis comes from the observation that in vitro insulin affects NE uptake by the atrial strips (39). On the other hand, the demonstration by microneurography that insulin increases the firing rate of the muscle sympathetic nerves is certainly supportive of a centrally mediated insulin effects but does not allow excluding a direct intervention of the hormone on muscle sympathetic endings. To explore the question whether insulin effect was at least in part accountable for by a direct peripheral effect, we infused insulin intrabrachially to raise the hormone concentration only locally in the forearm tissues. The validity of the model employed is supported by the fact that the arterial concentration of insulinsensitive substrates, such as glucose and particularly FFA, remained stable during local insulin infusion. With this approach, we failed to detect any appreciable change either in NE uptake or release by the muscle tissue. This leads to the conclusion that all of the insulin effect on muscle NE metabolism, seen with systemic insulinization, is mediated either by central mechanisms involving the hypothalamic nuclei or by a peripheral reflex. Regarding the latter, it seems quite unlikely that insulin may have elicited an arterial baroreflex since blood pressure remained unchanged throughout insulin infusion. On the other hand, one cannot exclude that insulin may have affected a different kind of peripheral reflex, e.g., a venous baroreflex or a chemoreflex.

In hypertensive patients, the increase in $\mathrm{NE}$ release induced by insulin was threefold greater than that observed in normotensive subjects. An increased sympathetic activity in hypertensive patients has been previously reported only in response to experimental maneuvers $(13,14)$. Our data demonstrate an increased responsiveness to a physiologic stimulus like insulin. This abnormal response of hypertensives was observed in circumstances where the forearm muscle tissue was exposed to a similar insulin concentration to that of normal subjects. However, it must be stressed that hypertensive patients are characterized by significantly higher postprandial insulin levels as compared with normal subjects $(10,40)$. Therefore, the phe- nomenon here revealed of insulin-induced sympathetic overactivity represents, in all likelihood, an underestimation of what may potentially occur in the day-life of hypertensive patients.

The marked increase in forearm $\mathrm{NE}$ release recorded in hypertensives during insulin infusion was not paralleled by significant changes in the hemodynamic parameters except for a small increase in heart rate. This is only in part surprising since several studies have shown that insulin may efficiently antagonize NE action on smooth muscle cells $(41,42)$. Nor is the hypothesis of a causal link between insulin and hypertension necessarily contradicted if one considers that sympathetic overactivity may affect the long-term regulation of arterial pressure. In this context, it is pertinent to recall that the sympathetic nervous system promotes the growth of vascular muscle fibers $(43,44)$ and myocardium $(45,46)$ and that NE can induce vascular smooth muscle cell polyploidy independent of blood pressure elevation (47). These are potential factors that may lead to structural alterations in the arterial vessels, thus reducing the lumen area, amplifying the vasoconstrictor response to contractile agents, and limiting vasodilation.

Forearm glucose uptake was similar in hypertensive and normotensive subjects during intrabrachial insulin infusion, demonstrating no difference in the direct effect of the hormone on skeletal muscle tissue, with regard to glucose uptake. On the other hand, during systemic insulinization, when indirect mechanisms also intervene (28), forearm glucose uptake was significantly lower in hypertensives than in normal subjects. This is seemingly in contrast with recent data showing muscle insulin resistance in hypertensives receiving intrabrachial insulin infusion (48). Actually, a careful perusal of those data reveals slight differences between normals and hypertensives at low insulin concentrations, similar to those used in the current study. On the other hand, the responses began to diverge markedly with high insulin infusion rates that gave clear signs of systemic insulinization.

The different response of muscle glucose uptake to local or systemic insulin may suggest that muscle insulin resistance in hypertension is entirely mediated by the indirect component of insulin action (28). Alternatively, the data may indicate that the exaggerated sympathetic activation induced by systemic insulinization in hypertensives may play a causal role in the impaired glucose uptake by the muscle tissue.

In conclusion, the current study provides evidence for an abnormal muscle sympathetic activity reflexly evoked by insulin in essential hypertension. The question whether hyperinsu- 
linemia is the primary defect leading to hypertension via this sympathetic overactivity cannot be answered by the current data. The alternative hypothesis that the primary event is a sympathetic overactivity leading to both hypertension and insulin resistance would be equally compatible with the current observations. Whatever the initial event, our data also point out the possibility that the abnormal sympathetic response to insulin may further aggravate insulin resistance and hyperinsulinemia, thus acting as a self-perpetuating mechanism in essential hypertension.

\section{Acknowledgments}

This work was supported in part by the Consiglio Nazionale delle Ricerche, Italy (grant 91.00427.PF40). G. Lembo was supported by a fellowship from the Italian Society of Arterial Hypertension.

\section{References}

1. Welborn, T. A., A. Breckenridge, A. H. Rubinstein, C. T. Dollery, and T. R. Fraser. 1966. Serum-insulin in essential hypertension and in peripheral vascular disease. Lancet. i: 1336-1337.

2. Modan, M., H. Halkin, S. Almog, A. Lusky, A. Eskol, M. Shefi, A. Shitrit, and Z. Fuchs. 1985. Hyperinsulinemia. A link between hypertension, obesity, and glucose intolerance. J. Clin. Invest. 75:809-817.

3. Reaven, G. M. 1991. Insulin resistance, hyperinsulinemia, and hypertrigliceridemia in the etiology and clinical course of hypertension. Am. J. Med. 90(Suppl. 2):7-12.

4. Hwang, I.-S., H. Ho, B. B. Hoffman, and G. M. Reaven. 1987. Fructose-induced insulin resistance and hypertension in rats. Hypertension (Dallas). 10:512516.

5. Reaven, G. M., and B. B. Hoffman. 1988. Attenuation of fructose-induced hypertension in rats by exercise training. Hypertension (Dallas). 12:129-132.

6. Reaven, G. M., H. Ho, and B. B. Hoffman. 1989. Somatostatin inhibition of fructose-induced hypertension. Hypertension (Dallas). 14:117-120.

7. Rocchini, A. P., J. Key, D. Bondie, R. Chier, C. Moorehead, V. Katch, and M. Martin. 1989. The effect of weight loss on the sensitivity of blood pressure to sodium in obese adolescents. $N$. Engl. J. Med. 321:580-585.

8. Ferrari, P., P. Weidmann, S. Shaw, D. Giachino, W. Riesen, Y. Allemann, and G. Heynen. 1991. Altered insulin sensitivity, hyperinsulinemia, and dyslipidemia in individuals with a hypertensive parent. Am. J. Med. 91:589-596.

9. Ferrannini, E., G. Buzzigoli, R. Bonadonna, M. A. Giorico, M. Oleggini, L. Graziadei, R. Pedrinelli, L. Grandi, and S. Bevilacqua. 1987. Insulin resistance in essential hypertension. $N$. Engl. J. Med. 317:350-357.

10. Shen, D. C., S. M. Shieh, M. T. Fuh, D. A. Wu, Y. D. I. Chen, and G. M. Reaven. 1988. Resistance to insulin-stimulated glucose uptake in patients with hypertension. J. Clin. Endocrinol. \& Metab. 66:580-583.

11. Rowe, J. W., J. B. Young, K. L. Minaker, A. L. Stevens, J. Pallotta, and L. Landsberg. 1981. Effect of insulin and glucose infusions on sympathetic nervous system activity in normal man. Diabetes. 30:219-225.

12. Anderson, E. A., R. P. Hoffman, T. W. Balon, C. A. Sinkey, and A. L. Mark. 1991. Hyperinsulinemia produces both sympathetic neural activation and vasodilation in normal humans. J. Clin. Invest. 87:2246-2252.

13. Anderson, E. A., C. A. Sinkey, W. J. Lawton, and A. L. Mark. 1989. Elevated sympathetic nerve activity in borderline hypertensive humans. Evidence from direct intraneural recordings. Hypertension (Dallas). 14:177-183.

14. Julius, S. 1990. Changing role of the autonomic nervous system in human hypertension. J. Hypertens. 8(Suppl. 7):59-65.

15. Izzo, J. L., Jr. 1984. The sympathoadrenal system in the maintenance of elevated arterial pressure. J. Cardiovasc. Pharmacol. 6:S514-S521.

16. Saccà, L., G. Perez, F. Rengo, I. Pascucci, and M. Condorelli. 1975. Effects of theophylline on glucose kinetics in normal and sympathectomized rats. Diabetes. 24:249-256.

17. Saccà, L., G. Perez, G. Carteni, and F. Rengo. 1977. Evaluation of the role of the sympathetic nervous system in the glucoregolatory response to insulin-induced hypoglycemia in the rat. Endocrinology. 101:1016-1022.

18. Saccà, L., N. Eigler, P. Cryer, and R. S. Sherwin. 1979. Insulin antagonistic effects of epinephrine and glucagon in the dog. Am. J. Physiol. 237:E487E492.

19. Diebert, D. C., and R. A. De Fronzo. 1980. Epinephrine-induced insulin resistance in man. J. Clin Invest. 65:682-689.

20. Saccà, L., C. Vigorito, M. Cicala, B. Ungaro, and R. S. Sherwin. 1982. Mechanisms of epinephrine-induced glucose intolerance in normal humans: role of the splanchnic bed. J. Clin. Invest. 69:284-293.

21. Capaldo, B., G. Lembo, R. Napoli, V. Rendina, G. Albano, L. Saccà, and
B. Trimarco. 1991. Skeletal muscle is a primary site of insulin resistance in essential hypertension. Metab. Clin. Exp. 40:1320-1322.

22. Saccà, L., R. A. Gelfand, and R. S. Sherwin. 1986. Epinephrine-insulin interactions in humans: dissociation of glucose and branched chain amino acid (BCAA) uptake by skeletal muscle. Diabetes. 35(Suppl. 1):83A. (Abstr.)

23. Kirkendall, W. M., M. C. Burton, F. M. Epstein, and E. D. Freis. 1967. Recommendations for human blood pressure determination by spygmomanometers. Circulation. 36:980-986.

24. Metropolitan Life Insurance Company. 1962. In Geigy Scientific Tables. 6th ed. Geigy Pharmaceuticals, Ardsley, NY. 623.

25. National Diabetes Data Group. 1979. Classification and diagnosis of diabetes mellitus and other categories of glucose intolerance. Diabetes. 28:10391057.

26. Andres, R., K. L. Zierler, H. M. Anderson, W. N. Sinsby, G. Cader, A. S. Gravyb, and J. L. Lilienthal, Jr. 1954. Measurement of blood flow and volume in the forearm of man: with notes on theory of indicator dilution and on production of turbolence, hemolysis, and vasodilation by intravascular injection. J. Clin. Invest. 33:482-504.

27. Saccà, L., M. Cicala, B. Trimarco, B. Ungaro, and C. Vigorito. 1982. Differential effects of insulin on splanchnic and peripheral glucose disposal after an intravenous glucose load in man. J. Clin. Invest. 70:117-126.

28. Capaldo, B., R. Napoli, P. Di Bonito, G. Albano, and L. Saccà. 1991. Dual mechanism of insulin action on skeletal muscle: identification of an indirect component not mediated by FFA. Am. J. Physiol. 260:E389-E394.

29. Noma, A., H. Okabe, and M. Chita. 1973. A new colorimetric microdetermination of free fatty acids from tissue stires. Clin. Chim. Acta. 43:317-322.

30. Debuquois, B., and G. D. Aurbach. 1971. Use of polyethylene glycol to separate free and antibody bound peptide hormones in radioimmunoassay. $J$. Clin. Endocrinol. \& Metab. 33:732-738.

31. Anton, A. H., and D. F. Sayre. 1962. A study of the factors affecting the aluminum oxide-trihydroxindole procedure for the analysis of catecholamines. $J$. Pharmacol. Exp. Ther. 138:360-382.

32. Trimarco, B., G. Lembo, N. De Luca, M. Volpe, B. Ricciardelli, G. Condorelli, G. Rosiello, and M. Condorelli. 1989. Blunted sympathetic response to cardiopulmonary receptor unloading in hypertensive patients with left ventricular hypertrophy. A possible compensatory role of atrial natriuretic factor. Circulation. 80:883-892.

33. Berne, C., J. Fagius, and F. Niklasson. 1989. Sympathetic response to oral carbohydrate administration. J. Clin. Invest. 84:1403-1409.

34. Young, J. B., and L. Landsberg. 1980. Impaired suppression of sympathetic activity during fasting in the gold thioglucose-treated mouse. J. Clin. Invest. 65:1086-1094.

35. Landsberg, L., and J. B. Young. 1985. Insulin mediated glucose metabolism in the relationship between dietary intake and sympathetic nervous system activity. Int. J. Obesity. 9:63-68.

36. Landsberg, L. 1986. Diet, obesity and hypertension: an hypothesis involving insulin, the sympathetic nervous system and adaptive thermogenesis. $Q . J$. Med. 236:1081-1091.

37. Van Houten, M., and B. I. Posner. 1983. Circumventricular organs: receptors and mediators of direct peptide hormone action on brain. Adv. Metab. Disord. 10:269-289.

38. Sauter, A., M. Goldstein, J. Engel, and K. Ueta. 1983. Effect of insulin on central catecholamines. Brain Res. 260:330-333.

39. Bhagat, B., W. J. Burke, and N. S. Dhalla. 1981. Insulin-induced enhancement of uptake of noradrenaline in atrial strips. Br. J. Pharmacol. 74:325-332.

40. Singer, P., W. Gödicke, S. Voigt, I. Hajdn, and M. Weiss. 1985. Postprandial hyperinsulinemia in patients with mild essential hypertension. Hypertension (Dallas). 7:182-186.

41. Alexander, W. D., and R. J. Oake. 1977. The effect of insulin on vascular reactivity to norepinephrine. Diabetes. 26:611-614.

42. Yagi, S., S. Takata, H. Kiyokawa, M. Yamamoto, Y. Noto, T. Ikeda, and N. Hattori. 1988. Effects of insulin on vasoconstrictive responses to norepinephrine and angiotensin II in rabbit femoral artery and vein. Diabetes. 37:10641067.

43. Bevan, R. D. 1984. Trophic effects of peripheral adrenergic nerves on vascular structure. Hypertension (Dallas). 6(Suppl. III):III19-III26.

44. Blaes, N. A., and J. P. Boissel. 1983. Growth-stimulating effect of catechulamines on rat aortic smooth muscle cells in culture. J. Cell. Physiol. 116:167172.

45. Simpson, P. 1983. Norepinephrine-stimulated hypertrophy of cultured rat myocardial cells in an alpha 1 adrenergic response. J. Clin. Invest. 72:732-738.

46. Trimarco, B., B. Ricciardelli, N. De Luca, A. De Simone, A. Cuocolo, M. D. Galva, G. B. Picotti, and M. Condorelli. 1985. Participation of endogenous catecholamines in the regulation of left ventricular mass in progeny of hypertensive parents. Circulation. 72:38-46.

47. Yamori, Y., M. Mano, Y. Nara, and R. Horie. 1987. Catecholamine-induced polyploidization in vascular smooth cell. Circulation. 75(Suppl. I):I92195.

48. Natali, A., D. Santoro, C. Palombo, M. Cerri, S. Ghione, and E. Ferrannini. 1991. Impaired insulin action on skeletal muscle metabolism in essential hypertension. Hypertension (Dallas). 17:170-178. 